\title{
Lingual anesthesia of the lower anterior teeth, which technique is better?
}

\author{
Saif Saadedeen Abdulrazaq ${ }^{1}$
}

Published online: 22 July 2019

(C) Springer-Verlag GmbH Germany, part of Springer Nature 2019

The gauge of the needle used was 27, which is the most commonly used in dentistry. As if we used, for example, silk suture in oral surgery, there is no need to mention the size of the suture as the most common size is $3 / 0$. In addition, several studies showed that there are no statistical or clinical differences between the most commonly used size of the gauge needles in dentistry (i.e., 25, 27, and 30 gauge) [1-4].

NOT the article cited [5] mention that "PDL technique could not be used for conservative treatment of primary teeth...," it was another article by Brannstrom et al. [6]. Moore et al. [5] just discussed it in his article. In addition, there are studies concluded that PDL injection could be used for conservative treatment of primary teeth [7-9].

\section{References}

1. Fuller NP, Menke RA, Meyers WJ (1979) Perception of pain to three different intraoral penetrations of needles. J Am Dent Assoc 99:822824

2. Mollen AJ, Ficara AJ, Provant DR (1981) Needles - 25 gauge versus 27-gauge — can patients really tell? Gen Dent 29:417-418

Saif Saadedeen Abdulrazaq

saifdento@gmail.com; drsaif.sa@ codental.uobaghdad.edu.iq

1 Department of Oral and Maxillofacial Surgery, College of Dentistry, University of Baghdad, Bab-Almoadham, P.O. Box 1417,

Baghdad, Iraq
3. Flanagan T, Wahl MJ, Schmitt MM, Wahl JA (2007) Size does not matter: needle gauge and injection pain. Gen Dent 55:216-217

4. Joanna SM, Sara AD, Richard T, Kraig SV (2015) Effect of needle design on pain from dental local anesthetic injections. Anesth Prog Spring 62(1):2-7

5. Moore PA, Cuddy MA, Cooke MR, Sokolowski CJ (2011) Periodontal ligament and intraosseous anesthetic injection techniques: alternatives to mandibular nerve blocks. J Am Dent Assoc 142(Suppl 3):13S-18S

6. Brannstrom M, Lindskog S, Nordenvall KJ (1984) Enamel hypoplasia in permanent teeth induced by periodontal ligament anesthesia of primary teeth. J Am Dent Assoc 109(5):735-736

7. Haghgoo R, Taleghani F (2015) Comparison of periodontal ligament injection and inferior alveolar nerve block in mandibular primary molars pulpotomy: a randomized control trial. J Int Oral Health 7(5):11-14

8. Baghlaf K, Elashiry E, Alamoudi N (2018) Computerized intraligamental anesthesia in children: a review of clinical considerations. J Dent Anesth Pain Med 18(4):197-204

9. Ashkenazi M, Blumer S, Eli I (2010) Effect of computerized delivery intraligamental injection in primary molars on their corresponding permanent tooth buds. Int J Paediatr Dent 20(4):270-275

Publisher's note Springer Nature remains neutral with regard to jurisdictional claims in published maps and institutional affiliations. 